\title{
A Sociolinguistic and Cross-cultural Investigation into the Speech Act of Suggestion
}

\author{
Mohammad Ali Heidari-Shahreza (Corresponding author) \\ Department of English, Faculty of Humanities, Shahreza Branch, Islamic Azad University \\ Pasdaran St., Shahreza, Isfahan, Iran \\ Tel: 98-321-329-2008Ｅ-mail: maheidari.sh@gmail.com
}

Received: December 10, 2013 Accepted: December 20, 2013 Published: December 24, 2013

doi:10.5296/ijch.v1i1.4722 URL: http://dx.doi.org/10.5296/ijch.v1i1.4722

\begin{abstract}
This study investigates the pragmatic strategies employed by 30 Iranian EFL learners in making suggestions in their L2. Their suggestions were compared with 30 American and another 30 Iranian students who made suggestions in their first language (English and Persian, respectively). Triangulated data obtained from DCT and open role-plays were analyzed based on three aspects of making suggestions at macro level (perspective, directness and politeness) and a number of micro strategies. While the general tendency was to make suggestions from the perspective of both the speaker and hearer $(\mathrm{S}+\mathrm{H})$ using almost direct language and redressive actions, at micro level significant differences were observed between the three groups of participants. Moreover, gender, relationship between interlocutors and the topic on which suggestions were made, also appeared to contribute to the observed differences. The findings of the study are discussed in the light of cross-cultural differences and its pedagogical implications are elaborated on.
\end{abstract}

Keywords: Suggestion, Pragmatic strategies, Speech act, Intercultural differences, Gender

\section{Introduction}

Learning a language is certainly much beyond learning grammar, vocabulary or its distinctive sounds (Guerra \& Martinez-Flor, 2006). While learning these mechanical features facilitate correct usage of language, it certainly falls short of its pragmatic, sociocultural aspect which is necessary for appropriate language use (see Alcón, 2001). In other words, in addition to 'linguistic' competence, learners need to have 'pragmatic' competence to be able to understand and communicate meanings and intentions appropriately in their L2 ( $\mathrm{Li}, 2010)$. Otherwise, breakdown or misunderstanding in communication may occur which is much less 
tolerable and by far more face-threatening for native speakers than simply committing errors in grammar or pronunciation of some words (Koike \& Pearson, 2005). Furthermore, due to inability to use language appropriately (or lack of pragmatic competence), native speakers may regard a learners' behavior as impolite and judge about his/her character (Nguyen, Hanh-Pham, \& Tam-Pham, 2012). Whereas, lack of grammatical knowledge, for instance, does not usually have such implication and such a speaker probably is considered as only a less proficient language user $(\mathrm{Li}, 2010)$.

Pragmatic competence includes knowledge of 'speech acts' (Nguyen, Hanh-Pham, \& Tam-Pham, 2012). A speech act is "the production of the sentence token under certain conditions" (Searle, 1979, p. 39). In a very broad sense, speech acts are acts of communication which correspond to the type of attitude being expressed (see Li, 2010). Language learners are very likely to misinterpret these speech acts, particularly if there are culturally vast differences between their first and second (or foreign) language (Allami \& Naeimi, 2011). Therefore, it is of primary importance to initially investigate and subsequently teach these speech acts as a part of learners' pragmatic competence so that they will be able to communicate appropriately and have a sound sociopragmatic judgment in their L2 (see Martinez-Flor, 2005).

The present study investigates the speech act of suggesting (or interchangeably, suggestion) in general and the strategies native and non-native speakers of English (i.e. Iranian Persian-speaking students) employ in making suggestions.

\subsection{The speech act of suggesting}

Suggestions belong to the group of directives which, according to Searle (1976), are those in which the speaker's purpose is to get the hearer to commit him/herself to some future course of action (Martinez-Flor, 2005). As Banerjee \& Carrell (1988, p. 319) state "an utterance that the speaker intends the hearer to perceive as a directive to do something that will be to the hearer's benefit".

Therefore, as Haverkate (1984) points out suggestion is distinguished from other directives such as requesting, pleading or ordering in that it is non-impositive. That is to say, the objective of suggestion is typically to benefit the hearer. Whereas the benefits obtained by carrying out an impositive speech act are exclusively for the speaker (Martinez-Flor, 2005).

In addition to being a directive, suggestions can be also regarded as components of a broader speech act that involves the act of advice. In fact, traditionally the terms 'suggestion' and 'advice' acts have been employed interchangeably to refer to the same speech act (Searle, 1969; Wardhaugh, 1985; Wierzbicka, 1987; Banerjee \& Carrell, 1988; Bardovi-Harlig \& Hartford, 1993, 1996; Tsui, 1994; Hinkel, 1997; Matsumura 2001, 2003). However, suggestions differ from advice first in that they carry a weaker force than advice (see Holmes, 1983; Richards, 1985) and secondly the propositional content of advice usually, if not always, directs the hearer to be the agent; whereas the propositional content of suggestion, either directs to the hearer or both the hearer and speaker.

In sum, a suggestion is a non-impositive directive speech act, with a weaker force than advice 
which expresses the belief that it is desirable for the hearer and/or the speaker to perform some future action $(\mathrm{Li}, 2010)$.

\section{Literature review}

Rintell (1979) was the first researcher to investigate the speech acts of requests and suggestions. She compared the degree of deference in these two speech acts and investigated how the factors, age and sex of the speaker and hearer affected the degree of deference in requests and suggestions produced by Spanish ESL learners. She found that at the pragmatic level, the learners used more deferent language when speaking in their native tongue.

Banerjee \& Carrell (1988) also explored the speech act of suggesting by employing a discourse completion test (DCT) consisting of 60 situations that elicited a suggestion. The study compared the performance of 28 Chinese and Malay speakers making suggestions in English in comparison with 12 native English speakers. The findings showed a similarity between the native speakers and non-native speakers in terms of frequency and level of directness on the one hand, and a difference in the number and types of politeness strategies on the other.

In another study, Koike (1996) addressed EFL learners' awareness of suggestions, proficiency level and L1 transfer in making suggestions in English with 114 Spanish EFL learners. The data was obtained from responses to a questionnaire that students had to complete after watching a videotape with seven speech acts. It appeared that proficiency level and L1 transfer can significantly contribute to strategic usage of suggestions in L2.

Alcón (2001) also examined the speech act of suggesting within the framework of status congruence in an ESL setting. She analyzed the tape-recorded making suggestions of 15 Spanish students, taking into account both frequency and form. Based on the percentage of direct forms and the absence of mitigators, Alcón (2001) concluded that non-native speakers (NNSs) could not be competent enough in making suggestions by merely being exposed to the language and pedagogical intervention is necessary in the context of academic advising sessions.

In this regard, also, Matsumura (2001, 2003) conducted a longitudinal study comparing two groups of Japanese learners of English in EFL and ESL settings. The study was primarily concerned with the degree of change that took place over time in the perception of the speech acts of suggestions and advice. The data were collected by means of a multiple-choice test, with 12 scenarios and four response choices for each scenario, which was administered four times throughout the academic year. Results from this study indicated that ESL learners' perception of these acts improved considerably more in comparison to EFL students over time. As Alcón (2001), the author suggests that learners in an EFL context may require some pedagogical intervention to become pragmatically competent.

Recently, Li (2010) compared the syntactic forms and pragmatic strategies in making suggestions adopted by a group of Chinese students in their L2 (English) with both a group of Australian students and another Cantonese group as control groups. Results indicated that while Cantonese students in their L2 used almost the same pragmatic strategies, they adopted 
few syntactic types and their sentences tended to be simpler.

The incentive behind the present study is that investigation of speech acts and the sociopragmatic factors which influence the various realization of language in different contexts have the potential to inform our approach to language teaching and extend our understanding of language beyond its linguistic surface to issues which ultimately determine learners' success or failure in real communication (see Guerra \& Martinez-Flor, 2006).

Furthermore, few studies have investigated the pragmatic strategies of making suggestions in comparison with other speech acts. What is more, even among these few studies, suggesting as a speech act mostly has received partial attention by the researchers since they have been also concerned with other speech acts such request or advice. Therefore, studies with a primary focus on pragmatic strategies of making suggestions are defensibly few (Li, 2010).

Finally, to the best of researchers' knowledge, this is the first study investigating the speech act of suggesting with a group of Persian speakers.

Three research questions guided the study:

1. What pragmatic strategies do Iranian EFL learners use in making suggestions in English (their L2)?

2. Are there any significant differences between their use of these strategies in comparison with L1 or L2 control groups?

3. Does gender play any significant role in making suggestions?

\section{Methodology}

The research questions were investigated through the use of written DCTs, and open role plays. Using DCTs and role plays together enabled the researcher to obtain sufficient, authentic data in a relatively short period of time. The triangulated data, then, was analyzed based on Li's categories of suggestion strategies to draw its major themes and patterns.

\subsection{Participants}

A total of 90 participants contributed to this research. There were three equal groups of participants. The participants of the first two groups were 60 first-year students of a university in Iran. The average age in both groups was 20. Both groups had started learning English from the first grade in junior high school. Therefore, they had been learning English for about 7 years at the time of participation in the study. Based on their English score in National University Entrance Exam and a subsequent placement test, final participants were all at lower-intermediate English proficiency level. A sociocultural background survey was also conducted to ensure that participants were suitable informants. Through this survey, it was assured that all final participants had the same sociocultural background. For example, they all came from middle-class families; spoke Persian as their first language (without any other dominant language) and did not have any significant exposure to English except through high school English classrooms or sporadically through mass media such as TV and movies. The third group of participants was 30 American college students in their first year of 
study in the U.S. Their average age was 20.5. A sociocultural survey was also conducted for American participants (as for the above groups). A summary of the information on the participants is provided in Table 1 below.

Table 1. Participants of the study

\begin{tabular}{lcccc}
\hline Group & Average age & Male & Female & Total number \\
\hline IEL $^{*}$ & 20 & 14 & 16 & 30 \\
\hline ICS $^{* *}$ & 20 & 15 & 15 & 30 \\
\hline ACS $^{* * *}$ & 20.5 & 17 & 13 & 30 \\
\hline
\end{tabular}

*Iranian EFL Learners; ** Iranian Control Students; ***American Control Students

\subsection{Materials}

\subsubsection{DCTs}

To elicit the participants' suggestions, a discourse completion task (DCT) with four situations was designed. The first situation was identical to the situation in role-plays (see part 3.2.2. for more information). That is to say, participants were asked to write down their suggestions to a classmate to take one of their mutual friends to beautiful places in the city. The main reason to choose the same situation both in DCTs and role-plays was to validate these two different data collection procedures against each other and to see if they converge or diverge. The other three situations (education, personal matter and work) differed from one another in terms of power/solidarity between interlocutors as well as the topic on which suggestions were made (see appendix 1). It was hoped that in this way a better understanding of strategy use in making suggestions in relation to other possible contributing factors would emerge.

\subsubsection{Role-Play Cards}

To compensate for the obvious shortcomings of DCTs and to have a better understanding of the pragmatic choices of participants in making suggestions, following Li (2010), an open role play was also used. The situation was identical to the first situation in the DCT. That is to say, each pair of participants (who were actually classmates) had the same friend who lived in a foreign country and was going to visit them shortly. They were supposed to discuss places to show him when he arrived in. Either of participants was given a role-play card with three places (vacation spots) on it. Out of these three places, the first place was identical in both cards, the second place was similar in nature but not the same and the third place was totally different. Each pair of participants was instructed to agree on only three places. This way both acceptance and rejection might emerge in their conversation which was believed to add to the role-play's authenticity. The places on the role-play cards were famous tourist attractions in their country (either Iran or The USA) which were quite familiar for the participants.

\subsection{Procedure}

After having successfully piloted the instruments of the study (both the DCT and role-play) 
with a target-like group of participants, firstly, all participants were sufficiently informed of the aims and scope of the study. Then, the DCTs were distributed. The participants were asked to imagine themselves in the situations and write down the answers they would naturally give in each situation. Afterwards, all participants were codified and their answers were classified based on Li's taxonomy (2010).

As for the role plays, the participants in each of the three groups were randomly paired to perform the role-play. They were sufficiently informed of the societal context of the role-play. All the role-plays took place inside the classrooms at university. The role plays were tape-recorded and codified for analysis.

\subsection{Analysis}

To analyze and classify the strategies used by the participants in making suggestions, Li's categories of pragmatic strategies in making suggestions was used. She takes into account three aspects, namely perspective, directness and politeness as shown in Table 2. Perspective refers to the point of view from which a suggestion is fulfilled (Li, 2010). In other words, it refers to the agent of the future action embedded in the suggestion which, theoretically speaking can have five different realizations (see Table 2 for different realizations of this aspect together with related examples).

As for the level of directness, based on the work by Blum-Kulka, et al (1998), Li (2010) identifies three levels of directness: 'direct' strategies in which the illocutionary force of the utterance is realized by grammatical means, 'conventionally indirect' strategies are the ones in which the illocutionary force of the utterance is expressed by fixed linguistic conventions established in the societal context of the role play and 'non-conventionally indirect' strategies which require the addressee to interpret the illocutionary force of the utterance using clues in the societal, pragmatic context.

Based on Brown and Levinson's theory of politeness (1987), the aspect of politeness was concerned with whether participants regarded their act of suggesting as a face-threatening act (FTA) so as to use some mitigating devices to lessen its threatening force or they used bald on record expressions (in Brown and Levinson's terms) without any redressive actions. As Li (2010) states:

"It is believed that while politeness strategy is a central issue in language performance, the choice of perspective and the role of conventionality indirectness can also represent important sources of variation".

These aspects have been reorganized here as having two levels: Macro level which refers to the aspects themselves and micro level which includes different pragmatic choices within each aspect.

An important decision to make in this study was to identify the units of analysis. Simply speaking, what to label as an act of suggestion amongst the utterances made by the participants had to be determined first. To do so, based on our definition of the speech act of suggestion as a directive speech act addressing hearer and/or the speaker to perform some 


\section{MlMacrothink}

future action, participants' utterances were analyzed first by the researcher and then by a rater. It is worth noting that in counting acts of suggestions, following Li (2010), the core of a suggestion act (the head act) was counted. Therefore, preceding optional elements such as fillers (e.g. well), discourse markers first, politeness markers (e.g. I think; If you ask me) or subsequent expressions such as "You should become a doctor. Doctors are usually rich", were considered as supportive moves preceding or following the head act and, therefore, were not counted as an act of suggestion in their own.

Table 2. Li's categories of suggestion strategies

\begin{tabular}{|l|l|l|}
\hline Macro & Micro & Examples \\
\hline Perspective & 1. Speaker dominance & "I can take him to City Park." \\
\cline { 2 - 3 } & $\begin{array}{l}\text { 2. Speaker + hearer } \\
\text { dominance }\end{array}$ & "We can invest our money" \\
\cline { 2 - 3 } & 3. hearer dominance & "You should be patient." \\
\cline { 2 - 3 } & 4. Implicit & "How about going to the movies?" \\
\cline { 2 - 3 } & 5. Other dominance & "He should take care of the problem" \\
\hline \multirow{2}{*}{ Directness } & 1. Direct & "Study harder!" \\
\cline { 2 - 3 } & 2. conversationally indirect & "How about going to the beach?" \\
\cline { 2 - 3 } & 3. non-conversationally & "I'm thinking of a nice vacation?" \\
\hline Politeness & 1. With redressive action & "You should be a doctor. You know, doctors are \\
& & rich." \\
\cline { 2 - 3 } & 2. Without redressive action & "You have to hurry!" \\
\hline
\end{tabular}

\section{Results}

In this section, the results of the study are presented in three parts. In the first part, the general patterns of making suggestions with respect to the three aspects of making suggestions (i.e. perspective, directness, politeness) are presented (macro level). While the main concern of this study is a comparative investigation of suggestion strategies among EFL learners, Iranian and American informants, it is believed that a closer look at characteristics of the individual situations in which suggestions are made as well as gender of the participants will shed light on the overall patterns and strategies used by these three groups. Therefore, in the second part, the dominant patterns observed between the three groups of participants are presented with regard to the four situations to see whether or not the general patterns would also hold true for each individual situation. Finally, in the third part of this section, the role of gender is also 


\section{Macrothink}

taken into account to discern the contribution of males and females in each group to the observed differences.

\subsection{General Patterns of Making Suggestions}

As Figure 1 shows, the general tendency for all the three groups of the participants is toward the use of 'speaker + hearer' strategy such as "we should take him to the park" without any significant differences between them (see Table 3 for some examples of suggestions made by the participants). However, minor differences in terms of perspective are also observed. That is to say, based on chi-square test, American informants have used significantly more 'implicit' strategies than the other two groups $\left(\chi^{2}=41.2345 ; \mathrm{df}=14 ; \mathrm{p}<0.005\right)$. Even so, they have employed significantly less 'other' strategies in making suggestions $(\chi 2=49.3762$; $\mathrm{df}=14 ; \mathrm{p}<0.005)$

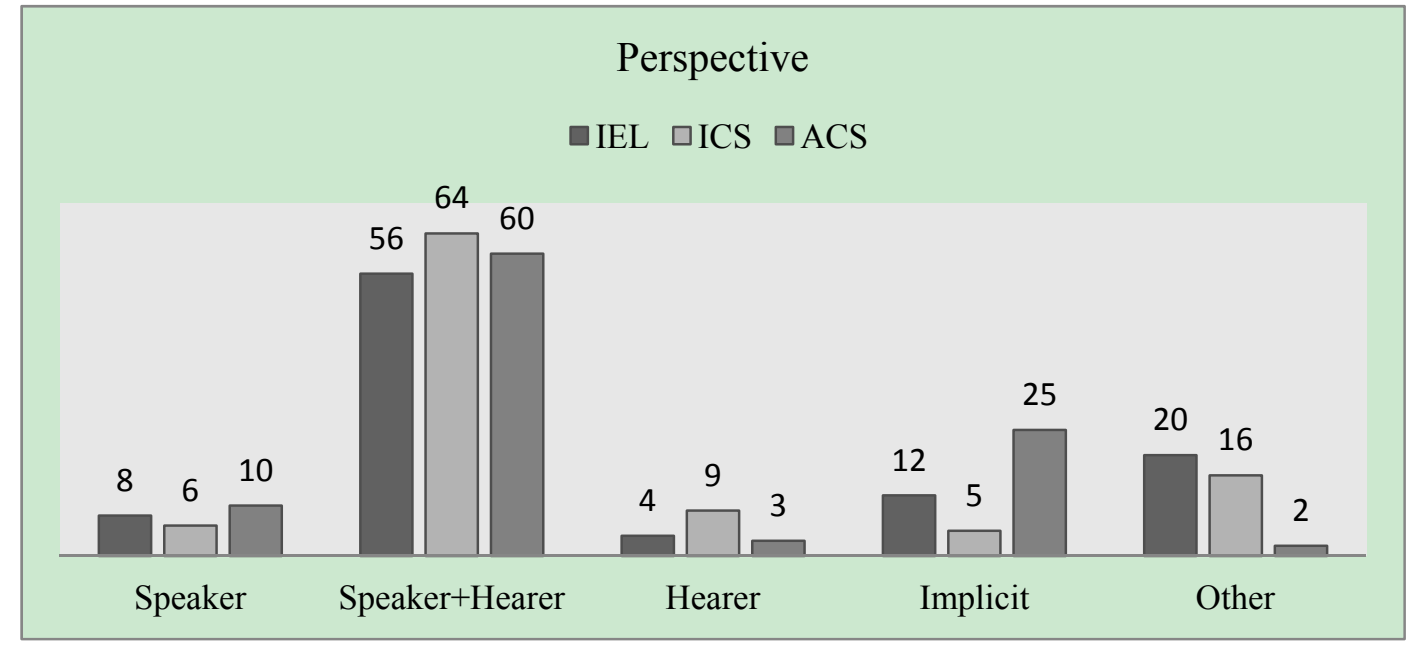

Figure 1. Perspective (participants's suggestions in percentage) 


\section{Macrothink}

Table 3. Examples of strategies made by the participants

\begin{tabular}{|c|c|}
\hline IEL & \\
\hline P30 & "we should take him to a park" \\
\hline P16 & "I can estimate the overall cost" \\
\hline $\mathrm{P} 12$ & "I'm think[ing] of biology" \\
\hline P4 & "Give him[her] time" \\
\hline \multicolumn{2}{|l|}{ ICS } \\
\hline P5 & "boro reshte pezeshki": "Choose medicine". \\
\hline P18 & "chetoreh berim park?": "How about going to a park?" \\
\hline $\mathrm{P} 23$ & "baxshe edari xeili mohemeh": "The office building is very important". \\
\hline P9 & "man bahash harf mizanam":"I'll talk to her". \\
\hline \multicolumn{2}{|l|}{ ACS } \\
\hline P7 & "let's take him to the movies" \\
\hline $\mathrm{P} 12$ & "Just be patient" \\
\hline $\mathrm{P} 23$ & “engineers have great jobs” \\
\hline $\mathrm{P} 2$ & "How about studying law" \\
\hline
\end{tabular}

Figure 2 shows the distribution of suggestion strategies with respect to level of directness. While the three groups have made use of almost the same number of 'conventionally indirect' strategies, ICS group has used significantly less 'direct' as well as more 'non-conventionally indirect' strategies than the other groups $(\chi 2=32.2459 ; \mathrm{df}=8 ; \mathrm{p}<0.005)$. Interesting to say, unlike the aspect 'perspective', in term of level of directness, EFL students have the same contribution of strategies as Americans do.

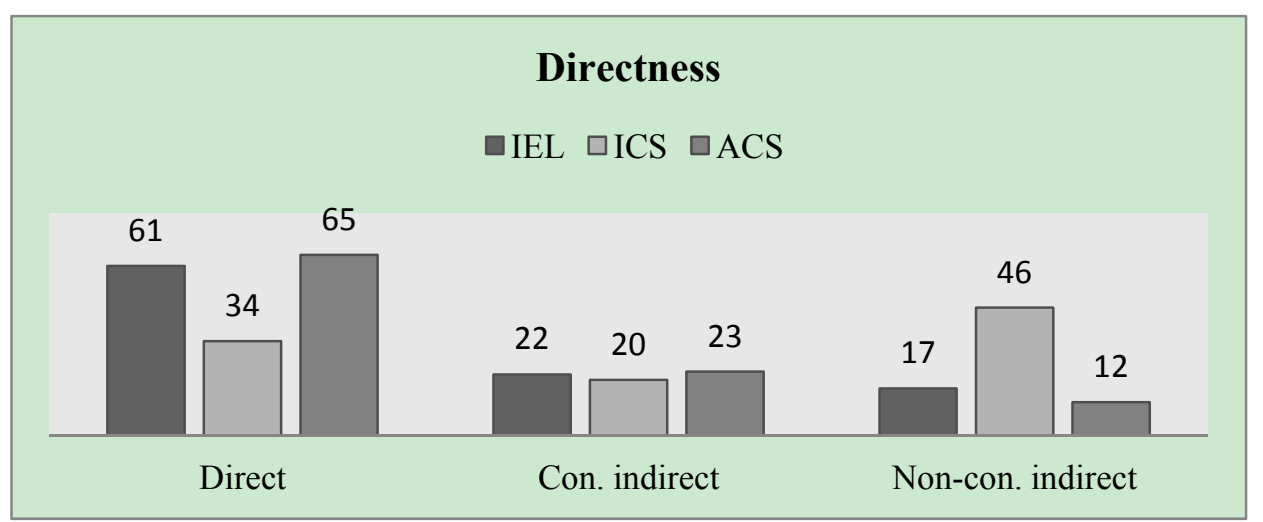

Figure 2. Directness (participants' suggestions in percentage) 


\section{Macrothink}

Figure 3 demonstrates the politeness aspect of making suggestions. A dominant pattern for all the participants is the use of redressive actions (mitigating devices) in making suggestions. In spite of this general similarity between the groups, Americans have significantly been more 'bald on record' (without redressive actions) $(\chi 2=23.6223 ; \mathrm{df}=5 ; \mathrm{p}<0.005)$

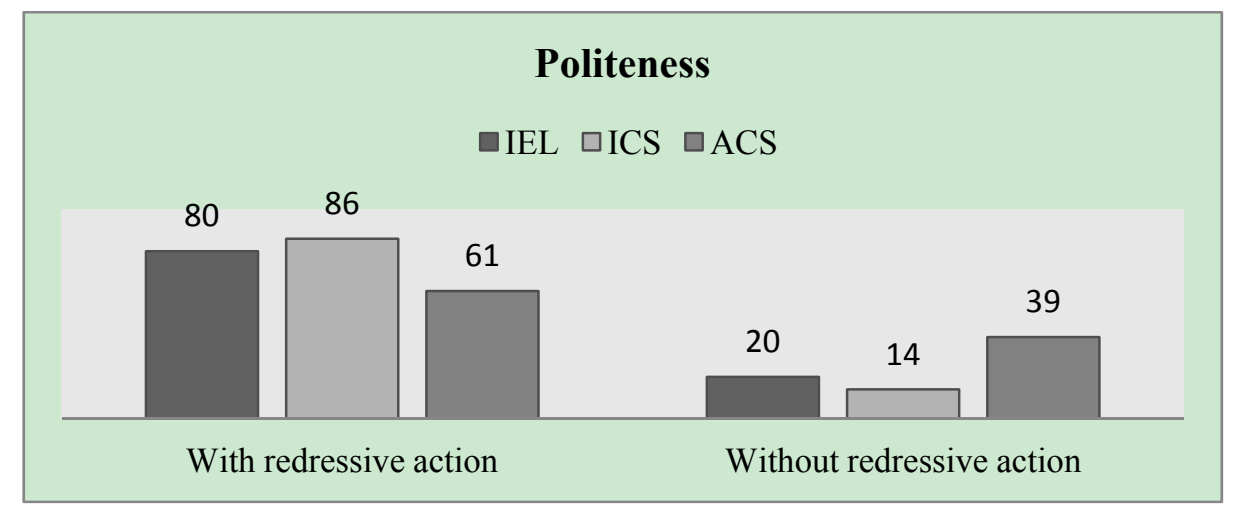

Figure 3. Politeness (participants' suggestions in percentage)

\subsection{Dominant Patterns across the Situations}

As it was revealed in the first part of this section, generally speaking, the dominant pattern in manking suggestions is to make suggestions from the perspective of both speaker and hearer $(\mathrm{S}+\mathrm{H})$ with an almost direct language and redressive actions. Despite this fact, an important question is whether or not this general tendecy holds true for all the situations.

As Table 4 and the asterisked figures indicate, in terms of perspective all the three groups have used less ' $\mathrm{S}+\mathrm{H}$ ' strategy in 'personal matter' and 'work' situations. In this regard, ICS group has used significantly less ' $\mathrm{S}+\mathrm{H}$ ' strategy in making suggestions in 'personal matter' situation (see discussion section for possible reasons for this difference) ( $\chi^{2}=35.1251$; $\mathrm{df}=14$; $\mathrm{p}<0.005$ ). The same pattern (as above) is observed for the level of directness. That is, less direct suggestions have been made by this group in the last two situations (i.e. personal matter and work). Also, Iranians have employed significantly less direct strategies than the other two groups.

Finally, in terms of politeness and the use of redressive actions, the participants generally have used less redressive actions in the first situation (i.e. trip for the mutual friend) than the other situations. However, this trend did not reach statistical significant $(\chi 2=16.2385 ; \mathrm{df}=5 ; \mathrm{p}$ $<0.005)$ 


\section{Ml Macrothink}

Table 4. Dominant patterns across situations

\begin{tabular}{|l|l|l|l|l|l|l|l|l|l|}
\hline \multirow{2}{*}{ Situation } & \multicolumn{3}{|l|}{ Perspective $(\rightarrow \mathrm{S}+\mathrm{H})$} & \multicolumn{3}{l|}{ Directness $\rightarrow$ direct $)$} & \multicolumn{3}{|l|}{ Politeness $\rightarrow$ redressive $)$} \\
\cline { 2 - 10 } & IEL & ICS & ACS & IEL & ICS & ACS & IEL & ICS & $A C S$ \\
\hline Trip & 69 & 79 & 70 & 67 & 44 & 76 & 65 & 75 & 49 \\
Education & 61 & 73 & 64 & 69 & 42 & 68 & 80 & 87 & 57 \\
Personal matter & 38 & $35^{*}$ & 52 & 47 & $21^{*}$ & 60 & 89 & 93 & 76 \\
Work & 56 & 69 & 54 & 59 & $31^{*}$ & 56 & 86 & 89 & 62 \\
\hline
\end{tabular}

\subsection{Gender and the Use of Suggestion Strategies}

As briefly discussed above, to shed more light on the use of suggestion strategies, the role of gender is also taken into account. As Figure 4 shows, there is no significant diffrence between male and female IEL in making suggestions. However, male Iranians (in ICS group) have used significantly more direct suggestions and less redressive actions in making suggestions than their female counterparts (see Figure 5) $\left(\chi^{2}=26.5895\right.$; $\left.d f=9 ; p<0.005\right)$. This pattern. However, does not hold true for Americans (ACS group). That is to say, male and female Americans almost have had the same amount of contribution (see Figure 6).

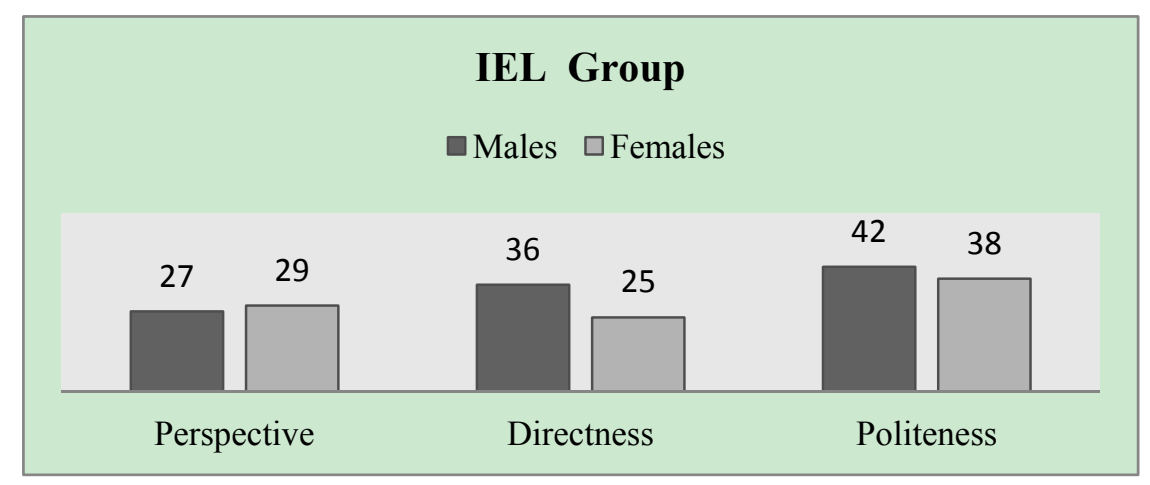

Figure 4. Iranian English students' suggestion with respect to gender

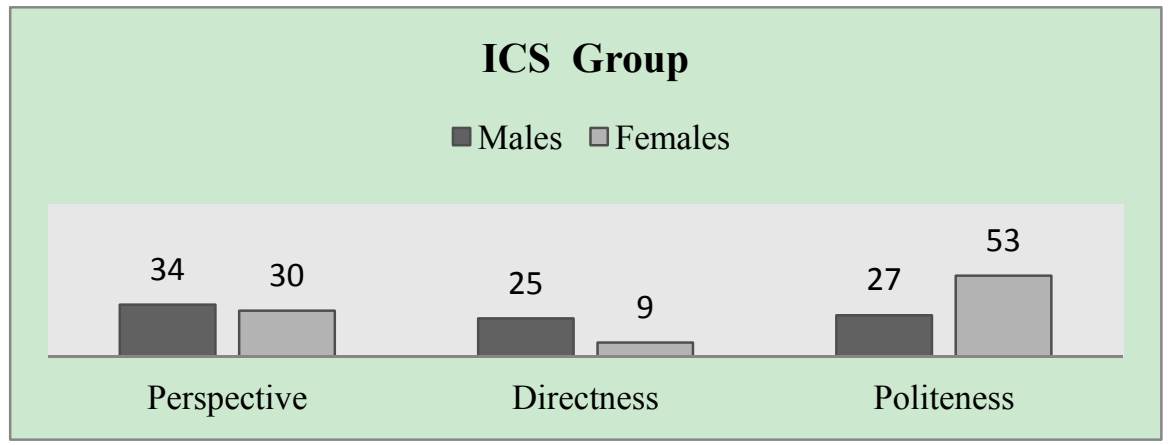

Figure 5. Iranian control students' suggestions with respect to gender 


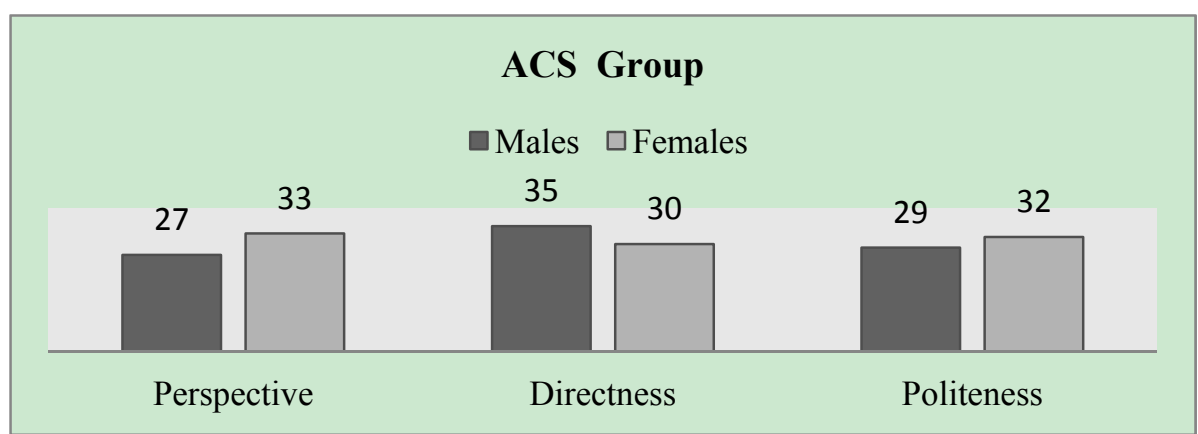

Figure 6. American control students' suggestions with respect to gender

\section{Discussion}

In the preceding section, the triangulated data (collected through DCTs and role-plays) were analyzed to discern how IEL, ICS and ACS groups were different or alike in making suggestions in role plays and four different settings.

\subsection{General Patterns in Making Suggestions}

Generally speaking, all the three groups of participants tended to make suggestions from the perspective of both the speaker and hearer $(\mathrm{s}+\mathrm{h})$ with a more or less direct language and redressive actions. In spite of this general similarity, significant differences were observed among the groups. In terms of perspective, Americans made significantly more suggestions from an implicit perspective such as "how about going to the park" and significantly less suggestions from an "other perspective such as "He should study biology" than the other groups. While it is very difficult to provide any reason for this observed difference, the scarcity of implicit structures such as "how about" in Persian (Iranians' first language) and its relative common occurrence in English might be a reason. Unfortunately, as for Persian, the researcher could not find any corpora to statistically test this hunch. As for 'other' perspective, it is not clear from the present data why IEL and ICS groups made significantly more suggestions. ICS group also made significantly less direct and more non-conventionally indirect suggestions than the other two groups (see Rintell, 1979; Li, 2010). This might originate from the fact that Iranians generally tend to be modest and indirect in their use of language as some related studies on invitation, compliment response, etc. also indicate (Sharifian, 2005, 2008; Salmani-Nodoushan, 2006b; Heidari-Shahreza, Vahid-Dastjerdi \& Marvi, 2011). The value culturally put on being modest and not assertive even at the cost of being more talkative, vague or insincere might explain the core difference between Iranians and Americans (Sharifian, 2005). An Iranian might try to conjure up an answer to a tourist asking for directions while he/she does not have any clue about the address being asked; or an Iranian might strongly invite you to come in and have tea while he/she is not ready for that indeed. This is what has been called by some scholars as ostensible invitation (Salmani-Nodoushan, 2006b). This might also explain why Iranians (ICS group) significantly made fewer suggestions without redressive actions.

IEL group made suggestions in their L2 (English) which resembles Americans in some ways and Iranians in some others. In terms of level of directness they significantly resemble 
Americans (see Banerjee \& Carrell, 1988). Whereas in politeness aspect of making suggestions they used almost the same number of redressive actions as Iranians did. The reason might be the fact that Iranian English learners particularly in an intermediate level of language proficiency are in a transitory stage between the pragmatic, cultural characteristics of their first language (Persian) and the target language (English). Therefore, up to the time a foreign language is culturally acquired (if ever), learners (here IEL group) might fluctuate in their linguistic behavior with possible resemblance to either languages (first language or second/foreign language) (cf. Koike, 1996). In addition, since the participants in IEL group were actually EFL (not ESL) learners, it is expected that due to their limited exposure to English language, they resemble Iranians (Persian speakers) more than Americans. Interesting to say, this is the case; IEL group, although not always significantly, resemble their Iranian counterparts (see Figure $1 \&$ Table 4).

\subsection{General Patterns across Situations}

The results showed that all the three groups of participants made fewer suggestions from the perspective of speaker and hearer and used a less direct language in 'personal matter' and 'work' situations. ICS's suggestions even were significantly less direct and less S+H than the other two groups. One possible explanation for the different strategy use of participants with respect to the last two situations might be the topic on which suggestion is made and the presupposed relationship between the interlocutors (see Rintell, 1979; Martinez-Flor, 2005). In the third situation, participants were to make suggestions on a very personal matter (one's relation with his/her partner). In the fourth situation, although the topic per se is not personal, the hearer was supposed to be the participant's boss at work who is normally much higher in power than the participant (the employee in the imagined situation). Therefore, topic and solidarity/power relationship between the interlocutors might have caused the observed difference in the use of strategies in different situations.

Another question here is why Iranian control students were significantly less direct and less $\mathrm{s}+\mathrm{h}$ than the other groups. The reason is possibly of religious, cultural nature. In Iranian Islamic culture, talking about someone's family or his familial problems is considerably a delicate and important issue which needs its own certain grounds (Sharifian, 2005). While a question like "How many sisters do you have?" or "what does your wife do?" seem quite appropriate to ask from a colleague or friend for an American, an Iranian needs to be much more careful in not threatening someone's negative face when asking such questions even after years of acquaintance with his friend or colleague. As predicted in part 5.1 about IEL group's linguistic behavior, they resemble their Iranian counterparts more than Americans.

\subsection{The Role of Gender in Making Suggestions}

Results showed that males in ICS group of participants significantly made more direct suggestions and used less redressive actions than their female counterparts in this group. Of course, the same trend was observed in IEL and ACS groups. But it did not reach statistical significant. The reason behind this observation might be the fact that Iranian culture is traditionally male-dominant and although nowadays Iranian society is progressing toward an equal or even female-dominant culture, this dominance is still notable (Sharifian, 2008). 
Moreover, gender differences in terms of independence and assertiveness may have played a role in the observed differences (see Chentsova-Dutton \& Tsai, 2007; Armentor-Cota, 2011 for information on gender differences).

\section{Conclusion}

The present study examined how Iranian EFL learners (IEL group) made suggestions in their L2 (English) in comparison with a group of American and a group of Iranian students making suggestions in their L1(English and Persian respectively). These two latter groups served as control groups to see how these learners' strategies in making suggestions were different or alike in comparison with either of the groups. The triangulated data (collected through DCTs and role plays) were analyzed based on Li's taxonomy of suggestion strategies (2010) that identifies three aspects in making suggestions namely, perspective, level of directness and politeness. Generally speaking, all the three groups of participants tended to make suggestions from the perspective of both the speaker and hearer $(s+h)$ with a more or less direct language and redressive actions. In spite of this general similarity, Iranian control students (ICS group) showed significant differences in the use of implicit or other perspective, use of direct strategies and amount of redressive actions in comparison with American control students (ACS group). As discussed above, IEL group made suggestions in their L2 (English) in a way which resembled Americans in some ways and Iranians in some others. For instance, in terms of level of directness they significantly resemble Americans whereas in politeness aspect of making suggestions, they used almost the same number of redressive actions as Iranians did.

A closer look at the individual situations in which suggestions were made as well as the gender of participants indicated that the topic on which suggestions are made and the relationship between the interlocutors in terms of power may contribute to their use of suggestions strategies. Additionally, male participants in ICS group tended to be significantly more direct than their female counterparts. However, this difference although existent in the other two groups (i.e. IEL \& ACS) did not reach statistical significance.

Learning a new language inevitably entails learning its pragmalinguistic and cultural features (Li, 2010). Successful language learning, particularly if it is conducive to actual use of language in authentic situations, requires being aware of how speech acts such as request, compliment, apology, congratulation, and of course suggestion are realized in the target language. This study is of notable importance to language teachers and material developers in that it demonstrates the significance of cross-cultural differences and the use of authentic language materials so that learners will be able to acquire pragmatic choices in their L2 (see also Guerra \& Martinez-Flor, 2006). Moreover, language teachers should attempt to improve learners' metapragmatic ability and cultural awareness so that they will be able to analyze language use in a conscious manner (Alcón, 2001; Matsumura 2001, 2003; Li, 2010).

Studies in sociolinguistics should be always interpreted with great care and caution. Because a plethora of factors might contribute to a researcher's observation which have/could not been taken into account, resulting in a profile of a sociolinguistic reality rather than its full face. Having admitted this common limitation, the present study only employed a limited number 
of young adult students in its two contexts (i.e. only one university in Iran and one in the U.S.A.). Furthermore, the data was collected through only four situations and role plays which could not include all possible topics or power/solidarity relationships between interlocutors which could have also made significant differences in our present picture of making suggestions in Persian and English. In addition, gender was only briefly addressed in this study while it certainly deserved a deeper investigation. Finally, the participants of IEL group were English learners at an intermediate level. The study would be more illuminating if an elementary and advanced group was also included.

Interested researchers can expand the scope of this study in different ways and address various aspects of making suggestions. As implied above, future studies may investigate gender, proficiency level or age in relation to making suggestions. They also may incorporate the syntactic choices made by EFL learners in their comparative studies of making suggestions. Another important venue for further research is also teaching of different suggestion strategies to English learners. Particularly in this regard, researchers can try to indentify which strategies cause problems for learners in their use or interpretation of suggestions.

\section{References}

Alcón, E. (2001). Developing pragmatic competence in the academic setting: The case of suggestions in NS/NNS advising sessions. In S. Posteguillo, I. Fortanet, \& J. C. Palmer (Eds.), Methodology and new technologies in language for specific purposes (pp. 79-86). Castelló: Servei de Publicacions de la Universitat Jaume I.

Allami, H., \& Naeimi, A. (2011). A cross-linguistic study of refusals: An analysis of pragmatic competence development in Iranian EFL learners. Journal of Pragmatics, 43, 385-406. http://dx.doi.org/10.1016/j.pragma.2010.07.010

Armentor-Cota, J. (2011). Multiple Perspectives on the Influence of Gender in Online Interactions. Sociology Compass, $\quad$ 23-36. http://dx.doi.org/10.1111/j.1751-9020.2010.00341.x

Banerjee, J., \& Carrell, P. L. (1988). Tuck in your shirt, you squid: suggestions in ESL. Language Learning, 38, 313-347. http://dx.doi.org/10.1111/j.1467-1770.1988.tb00416.x

Chentsova-Dutton, Y. E., \& Tsai, J. L. (2007). Gender Differences in Emotional Response among European Americans and Hmong Americans. Cognition and Emotion, 21(1), 162-181. http://dx.doi.org/10.1080/02699930600911333

Eisenstein, M., \& Bodman, J. W. (1986). "I very appreciate": expressions of gratitude by native and nonnative speakers of American English. Applied Linguistics, 7, 167-185. http://dx.doi.org/10.1093/applin/7.2.167

Guerra, A. F., \& Martinez-Flor, A. (2006). Is teaching how to suggest a good suggestion? An empirical study based on EFL learners' accuracy and appropriateness when making suggestions. Porta Linguarum, 5, 91-108. 
Haverkate, H. (1984). Speech acts, speakers and hearers, Pragmatics and beyond. Amsterdam: John Benjamins. http://dx.doi.org/10.1075/pb.v.4

Heidari-Shahreza, M. A., Vahid-Dastjerdi, H., \& Marvi, S. (2011). Discoursal variation and gender: The case of compliment responses among male and female speakers. Mediterranean Journal of Social Sciences, 2(3), 159-168.

Hinkel, E. (1997). Appropriateness of Advice: DCT and Multiple Choice Data. Applied Linguistics, 18(1), 1-26. http://dx.doi.org/10.1093/applin/18.1.1

Holmes, J. (1983). The structure of teachers' directive. In J. C. Richards, \& R. W. Schmidt (Eds.), Language and Communication. Cambridge: Cambridge University Press.

Jansen, F., \& Janssen, D. (2010). Effects of positive politeness strategies in business letters. Journal of Pragmatics, 42, 2531-2548. http://dx.doi.org/10.1016/j.pragma.2010.02.013

Koike, D. A. \& Pearson, L. 2005. The effect of instruction and feedback in the development of pragmatic competence. System, 481-501. http://dx.doi.org/10.1016/j.system.2005.06.008

Li, E. S. H. (2010). Making suggestions: A contrastive study of young Hong Kong and Australian students. Journal of Pragmatics, 42, 598-616. http://dx.doi.org/10.1016/j.pragma.2009.07.014

Martinez-Flor, A. (2005). A Theoretical Review of the Speech Act of Suggesting: Towards a Taxonomy for its Use in FLT. Revista Alicantina de Estudios Ingleses, 18, 167-187

Matsumura, S. (2001). Learning the rules for offering advice: A quantitative approach to second language socialization. Language learning, 51, 635-679. http://dx.doi.org/10.1111/0023-8333.00170

Matsumura, S. (2003). Modeling the relationships among interlanguage pragmatic development, L2 proficiency, and exposure to L2. Applied Linguistics, 24(4), 465-491. http://dx.doi.org/10.1093/applin/24.4.465

Nguyen, T. T. M., Pham, T. H., \& Pham, M. T. (2012). The relative effects of explicit and implicit form-focused instruction on the development of L2 pragmatic competence. Journal of Pragmatics, 44, 416-434. http://dx.doi.org/10.1016/j.pragma.2012.01.003

Richards, J. C. (1985). The Context of Language Teaching. Cambridge: Cambridge University Press.

Rintell, E. (1979). Getting your speech act together: The pragmatic ability of second language learners. Working Papers on Bilingualism, 17, 97-106.

Salmani-Nodoushan, M. A. (2006). A Comparative, Sociopragmatic Study of Ostensible Invitation in English and Farsi. Speech Communication, 48, 903-912. http://dx.doi.org/10.1016/j.specom.2005.12.001

Schmidt, R., \& Richards, J. (1985). Speech acts and L2 learning. In J. Richards (Ed.), The 
Context of Language Teaching (pp. 100-128). Cambridge: Cambridge University Press.

Searle, J. R. (1969). Speech acts: An essay in the philosophy of language. Cambridge: Cambridge University Press. http://dx.doi.org/10.1017/CBO9781139173438

Searle, J. R. (1976). The classification of illocutionary acts. Language in Society, 5, 1-24. http://dx.doi.org/10.1017/S0047404500006837

Searle, J. R. (1979). Expression and Meaning: Studies in the Theory of Speech Acts. Cambridge: Cambridge University Press. http://dx.doi.org/10.1017/CBO9780511609213

Sharifian, F. (2005). The Persian cultural schema of "shekasteh-nafsi": A study of compliment responses in Persian and Anglo Australian speakers. Pragmatics and cognition, 13(2), 337-362. http://dx.doi.org/10.1075/pc.13.2.05sha

Sharifian, F. (2008). Cultural Schemas in L1 and L2 Compliment Responses: A Study of Persian-speaking Learners of English. Journal of Politeness Research, 4(1), 55-80.

Tang, C. H., \& Zhang, G. Q. (2008). A contrastive study of compliment responses among Australian English and Mandarin Chinese speakers. Journal of Pragmatics, 41(2), 325-345. http://dx.doi.org/10.1016/j.pragma.2008.05.019

Tsui, A. (1994): English conversation. Oxford: Oxford University Press.

Wardhaugh, R. (1985): How conversation works. Cambridge, MA: Basil Blackwell.

Wierzbicka, A. (1987): English speech act verbs. A semantic dictionary. Sydney, Orlando: Academic Press.

\section{Appendix}

Appendix 1. Survey on Complement Responses

\section{(English Translation):}

Dear participant: This survey is designed to study making suggestions strategies among Iranian and American informants. Please fill in the questionnaire carefully in order to help us fulfill this survey. Your participation is greatly appreciated.
Name:
Nationality:
Age:

Your first language (mother tongue):

Sex: male

female

\section{English Level (if you are an EFL learner):}

\section{Instructions:}

You are given four situations in which you make suggestions. Please imagine yourself in these situations. Then write down the reply you are most likely to naturally give.

Only write down your actual reply not any explanation. 


\section{Macrothink

\section{Situation 1 (trip)}

Your classmate and you have a mutual foreign friend who is going to stay for a few days in your country. How do you make a suggestion about taking him/her to beautiful places in your country?

You answer:

\section{Situation 2 (education)}

One of your friends needs your suggestions on choosing the right major to study in university. How do you suggest?

You answer:

\section{Situation 3 (personal matter)}

Your cousin has had quarrels with his/her partner recently. He/she is thinking of breaking up. Suggest your cousin on this matter.

\section{You answer:}

\section{Situation 4 (work)}

Your boss is asking for your opinion on renewing the machinery and where/how to start? What do you suggest?

\section{You answer:}

\section{Copyright Disclaimer}

Copyright reserved by the author(s).

This article is an open-access article distributed under the terms and conditions of the Creative Commons Attribution license (http://creativecommons.org/licenses/by/3.0/). 